\title{
A comparison of the modern and classic golf swing: a clinician's perspective
}

\author{
Andrew McHardy ${ }^{1}$ (B Med Sc, MChiro, Grad Dip Chiro Paed, PhD (Cand)) \\ Henry Pollard ${ }^{1}$ (Grad DC, Grad Dip App Sc, M Sport Sc, PhD) \\ Greg Bayley ${ }^{2}$ (B Sp Sc)
}

${ }^{1}$ Macquarie Injury Management Group, Department Health \& Chiropractic, Macquarie University, Sydney, Australia

${ }^{2}$ Member Australian PGA

\begin{abstract}
Objective. There is little descriptive research on the motion the body displays during the golf swing. The purpose of this research is to review the modern golf swing and compare its motion to the classic golf swing.

Discussion. The comparison revealed subtle but significant differences in the backswing and the follow-through positions. The potential implications for power and injury, particularly of the lower back, are discussed. The discussion describes a third swing, the hybrid swing, which is a combination of the classic and modern swing. The hybrid swing may potentially reduce the chances of sustaining a low back injury while still retaining the power of the modern swing.

Conclusion. The golf swing has evolved over time as a result of a combination of advanced equipment, course design and human experimentation. The hybrid swing is being taught by some golf professionals as a balance between the power-potential of the modern swing and the 'back-friendly' nature of the classic swing, though no studies have so far been conducted on its efficacy. Further investigation into the three golf swings, classic, modern and hybrid, is required to determine which swing is the most effective while also being friendly to the body. Such research will make possible the development programmes aimed at reducing golf injury rates, particularly to the lower back.
\end{abstract}

\section{CORRESPONDENCE:}

Andrew McHardy

PO Box 448

Cronulla

NSW 2230

Australia

E-mail: ajmchardy@optushome.com.au

\section{Introduction}

In the hands of a champion the golf swing is a complex movement of great power and beauty. Despite the image of a single type of swing, the swing can be modified through the use of different equipment and is dependent on the level of skill and physical characteristics of those that use it. While each golfer has a unique swing, two swing types are predominately used, the classic swing and the modern swing. The classic swing was dominant until the 1960s when Jack Nicklaus altered the 'face of golf' by producing shots that achieved great height and distance with a new swing termed the modern swing. Such is the popularity of the modern golf swing, that golf emblems like the American PGA tour logo display the traditional form of the modern golf swing. Indeed, the modern golf swing is quite common in the professional ranks, with high-profile older golfers such as Greg Norman, Fred Couples and Tom Watson using the modern golf swing, particularly in their prime. Today's golfers also display this golf swing, Colin Montgomerie, Tiger Woods and Adam Scott, to name a few, with many young golfers wanting to emulate this type of golf swing.

Knowledge of the differences in the golf swing can assist the practitioner in the management and prevention of golfrelated injury. Furthermore, as a golfer ages and loses range of motion, sprain/strain injury may result. Such golfers may benefit from a modification of their golf swing that is suited to their physical capabilities. The purpose of this paper is to provide a descriptive overview of the classic and modern golf swings in a right-handed golfer. A discussion of how these swings can influence the potential for injury is also presented. Finally, the authors propose a third swing: the hybrid swing, which combines elements of the classic and modern swings. The hybrid swing aims to capture the advantages of each swing without the deleterious effects of injury.

\section{Background}

There are any number of golfing magazines and instructional books that describe the golf swing, and many important 

TABLE I. Predominant muscle activity during the golf swing

\begin{tabular}{|c|c|c|}
\hline & Muscles most active - upper body & Muscles most active - Lower body/trunk \\
\hline Backswing & $\begin{array}{l}\text { Left subscapularis } \\
\text { Right upper trapezius }\end{array}$ & $\begin{array}{l}\text { Left erector spinae } \\
\text { Right semimembranosus }\end{array}$ \\
\hline Early downswing & $\begin{array}{l}\text { Left rhomboids } \\
\text { Right pectoralis major }\end{array}$ & $\begin{array}{l}\text { Left vastus lateralis } \\
\text { Right gluteus maximus }\end{array}$ \\
\hline Acceleration & Pectoralis major bilaterally & $\begin{array}{l}\text { Left biceps femoris } \\
\text { Right abdominal oblique }\end{array}$ \\
\hline Impact & $\begin{array}{l}\text { Increased forearm flexor activity, termed the } \\
\text { flexor burst }\end{array}$ & \\
\hline Early follow-through & Pectoralis major bilaterally & $\begin{array}{l}\text { Left long head of biceps femoris } \\
\text { Right gluteus medius }\end{array}$ \\
\hline Late follow-through & $\begin{array}{l}\text { Left infraspinatus } \\
\text { Right subscapularis }\end{array}$ & $\begin{array}{l}\text { Left semimembranosus } \\
\text { Right vastus lateralis }\end{array}$ \\
\hline
\end{tabular}

studies performed on the golf swing in the right-handed golf$\mathrm{er}^{5,9,12,42}$, commencing with Rehling ${ }^{46}$ in 1955 and most recently by Egret et al. ${ }^{11}$ Particular areas of attention include the lower back/trunk, ${ }^{40,41}$ shoulder/upper body, ${ }^{6,22,24,39,45}$ forearm/ wrist, ${ }^{8,15}$ knee, ${ }^{4,13}$ and the foot-ground interaction during the golf swing. ${ }^{2,25,47,54}$ Analysis of the golf swing has progressed from 2-dimensional kinetic analysis to 3-dimensional analysis, $^{42}$ as well as kinematic ${ }^{35}$ and electromyographic (EMG) analysis. Kinetic analysis of the golf swing investigates the forces in the golf swing that produce movement, while kinematic analysis provides information on the geometrical form of the golf swing, but does not provide data on forces encountered in the golf swing. EMG analysis provides information on muscle activity that produces the movement used by the body to produce the golf swing. Pure kinematic analysis involves theta angles and plots of $x, y$ and $z$ co-ordinates that can be used to examine force vectors encountered during the golf swing at specific sites. Many of the data collected are difficult to interpret for non-biomechanist clinicians.

Kinetic analysis of the golf swing, which examines forces produced during the golf swing allows the investigator to identify the loads on specific areas of the body. These studies can help practitioners understand where the body may be prone to excessive forces that may lead to inefficient movement or injury. Such studies have found that the lower back encounters excessive loading of lateral bending, axial rotation, shear forces and compression. ${ }^{20}$ The forces described above have peak levels during the terminal downswing and acceleration phases of the golf swing, and amateur golfers experience greater forces than professional golfers. ${ }^{20}$ Experiments have revealed that the right knee experiences its peak force at the end of the backswing when the club is moving slowly, while the left knee demonstrates peak force near impact and follow-through. ${ }^{13}$ Analysis of motion displayed during the golf swing at distinct areas of the body (shoulder, ${ }^{39}$ wrist, ${ }^{8}$ low back, ${ }^{27,37}$ foot, ${ }^{57}$ knee $^{13}$ ) have also been performed. These studies analyse a generic golf swing with no particular reference to the type of swing, nor do they highlight the possibility of different types of swings.

By contrast to the kinematic analyses, a number of EMG studies have analysed the muscle activity that occurs during the golf swing of both the upper body/limb $b^{14,23,24,45}$ and lower body/lower trunk..$^{4,44,55}$ These studies investigated the proportion of maximal contraction in muscles activated during different phases of the swing. Again, none of these studies have referred to the possibility of different types of golf swing. A summary of major EMG findings during the golf swing can be seen in Table I. For more detailed review of EMG studies, the reader is directed to McHardy and Pollard. ${ }^{32}$

The subjects used in the majority of the EMG studies have been professional or high-level amateur golfers. As these golfers make up approximately $5 \%$ of all golfers, consideration should be given to the concept that the golf swings examined in these studies may not be representative of the average golfer, and therefore the findings of these studies may not reasonably be extrapolated to the average golfer.

The swings analysed in these studies may be classed as 'generic' swing types as no description of swing characteristics are mentioned. However, two discrete swing have been identified, the classic and the modern golf swings. Little scientific study has been conducted on the difference between the modern and classic golf swings. While all golf swings are unique, and are dependant on individual age, gender and physical characteristics, they fall within broad classifications and there is a need to describe distinct swing types. Classifications are important as they allow a practitioner to recognise and correlate the golf swing described within the literature to the golf swing of their patients. Stover et al. ${ }^{49}$ briefly described the modern golf swing, while Adlington ${ }^{1}$ attempted to instruct in mechanics of the golf swing and Sherman and Finch ${ }^{48}$ outlined a checklist of factors that would create the perfect golf swing. Hosea and Gatt ${ }^{19}$ briefly mentioned the two types of golf swing in a review of back pain in golf. Despite these cursory attempts, there has been no kinematic or kinetic analysis of a comparison of the classic and modern golf swings. This paper attempts to provide the practitioner with a practical anatomical model of the modern and classic golf swing and highlight the differences displayed between the two swing types.

\section{The golf swing}

It must be noted that the golf swing is individualistic and each person has a unique swing that incorporates factors such as 

age, height, weight and flexibility. The descriptions provided henceforth are general characteristics of the two most common swing types. The golf swing can be divided into a number of postures and phases that occur during the process of swinging the club to hit the ball (Table II, Figs 1 - 4). A summary of the modern and classic golf swing in each phase is given in Table III.

The following descriptions of the modern and classic golf swings are based on roundtable professional golfer consensus and studies examining joint motion ranges of the golf swing. It must be noted that there is a need to quantify these descriptions with future biomechanical studies (kinetic, kinematic and EMG) of the modern and classic golf swings.

\section{Address (in the right-handed golfer)}

The address position of the classic and modern golf swing is similar. At the address position the feet are slightly splayed out (slight hip/knee external rotation), the left at approximately $20-30^{\circ}$ to square and the right at about $10^{\circ}$. The knees are slightly flexed (as comfortable, approximately $20-25^{\circ}$ ), as are the hips. ${ }^{21,28}$ The neck is flexed to look at the ball. In the address position, the shoulders are slightly flexed and adducted to form an upturned triangle, with a line drawn across the shoulder being the base and the hands being the apex. Because the right hand is situated below the left when gripping the club, there is a right lateral flexion of the spine of approximately $16^{\circ}$ which results in the left shoulder being higher than the right when viewed from behind. ${ }^{14,21}$ Weight is distributed evenly onto both feet with the forefoot taking the majority of weight. ${ }^{2}$ The centre of gravity runs through the shoulders, the knees and the mid-foot.

\section{The backswing}

The backswing is characterised by a rotation of the shoulder girdle to the right, anatomically resulting in right-scapula retraction and left-scapula protraction as the scapulas move around the trunk in a clockwise movement. This results in the upper and middle trapezius on the right and the subscapularis on the left being the most active muscles in the upper body, with the rhomboids also active. ${ }^{15,24,32,45}$ The pelvic muscles provide a stable base for the trunk to rotate, while lumbopelvic movement results from hamstring group activation as the body weight transfers to the right side.

\section{Top of the backswing}

The degree of upper-body rotation at the top of the backswing creates a tightly coiled body to store energy that produces the clubhead speed seen at impact. ${ }^{52}$ In the modern swing, the upper body is fully rotated, from $80^{\circ}$ to approximately $110^{\circ}$, depending on characteristics of the golfer such as age/flexibility. ${ }^{6,37}$ McTeigue et al. ${ }^{37}$ in 1994 found senior PGA tour professionals displayed nearly $80^{\circ}$ upper body ro-

\section{TABLE II. Summary of the phases/postures of the golf swing}

\begin{tabular}{|c|c|}
\hline Golf swing phase/posture & Description \\
\hline Address & The position that the player adopts in preparation to initiate the golf swing \\
\hline Backswing & $\begin{array}{l}\text { Initial movement of club } \\
\text { Swings in arc away from ball } \\
\text { Ends when shaft of club is parallel to ground, with clubhead facing target }\end{array}$ \\
\hline Top of backswing & End of backswing, before the initiation of downswing \\
\hline Downswing & $\begin{array}{l}\text { Club returns along a similar path to that of the backswing in preparation to hit the ball } \\
\text { Ends with shaft parallel to ground }\end{array}$ \\
\hline Acceleration & $\begin{array}{l}\text { From shaft horizontal to impact } \\
\text { Most active part of swing }\end{array}$ \\
\hline Impact & The clubhead hits the ball \\
\hline Early follow-through & From impact to club horizontal to ground \\
\hline \multirow[t]{2}{*}{ Late follow-through } & From club horizontal to end of swing \\
\hline & Results in the hands finishing over the left shoulder \\
\hline
\end{tabular}

TABLE III. Differences between the modern and classic golf swing

\begin{tabular}{|c|c|c|}
\hline & Modern golf swing & Classic golf swing \\
\hline Address & Similar to classic & Similar to modern \\
\hline Backswing & Early wrist cocking & Late wrist cocking \\
\hline Top of backswing & $\begin{array}{l}\text { Limited pelvic rotation compared to shoulder rotation } \\
\text { Limited body movement to right } \\
\text { All of left foot on ground (bar lateral aspect) }\end{array}$ & $\begin{array}{l}\text { Equal amounts of pelvic and shoulder rotation } \\
\text { Large movement of body to right } \\
\text { Only left toes in contact with ground }\end{array}$ \\
\hline Downswing & Hips initiate downswing & Whole body initiates downswing \\
\hline Impact & $\begin{array}{l}\text { Hips ahead of shoulders } \\
\text { Relatively large degree of right lateral flexion in trunk }\end{array}$ & $\begin{array}{l}\text { Hips equal with shoulders } \\
\text { Low amount of right lateral flexion in trunk }\end{array}$ \\
\hline Follow-through & $\begin{array}{l}\text { Hyperextension in lower back } \\
\text { Momentum directed upwards }\end{array}$ & $\begin{array}{l}\text { Lower back in relatively neutral position } \\
\text { Momentum directed forwards }\end{array}$ \\
\hline
\end{tabular}





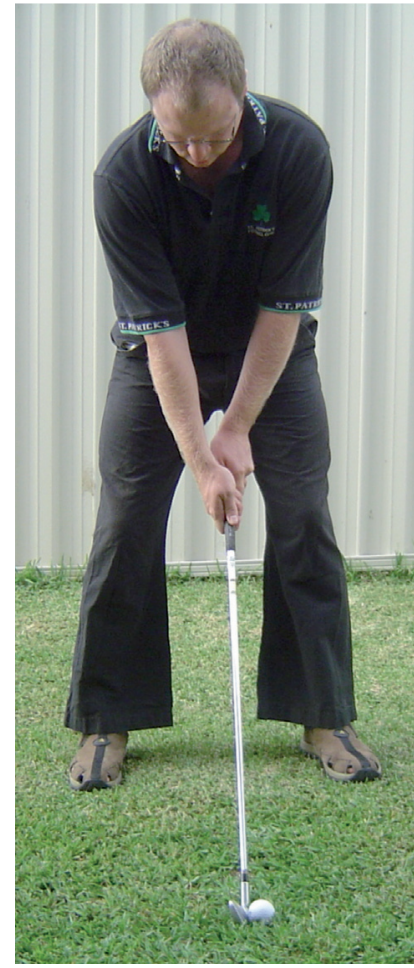

Fig. 1. The address position.

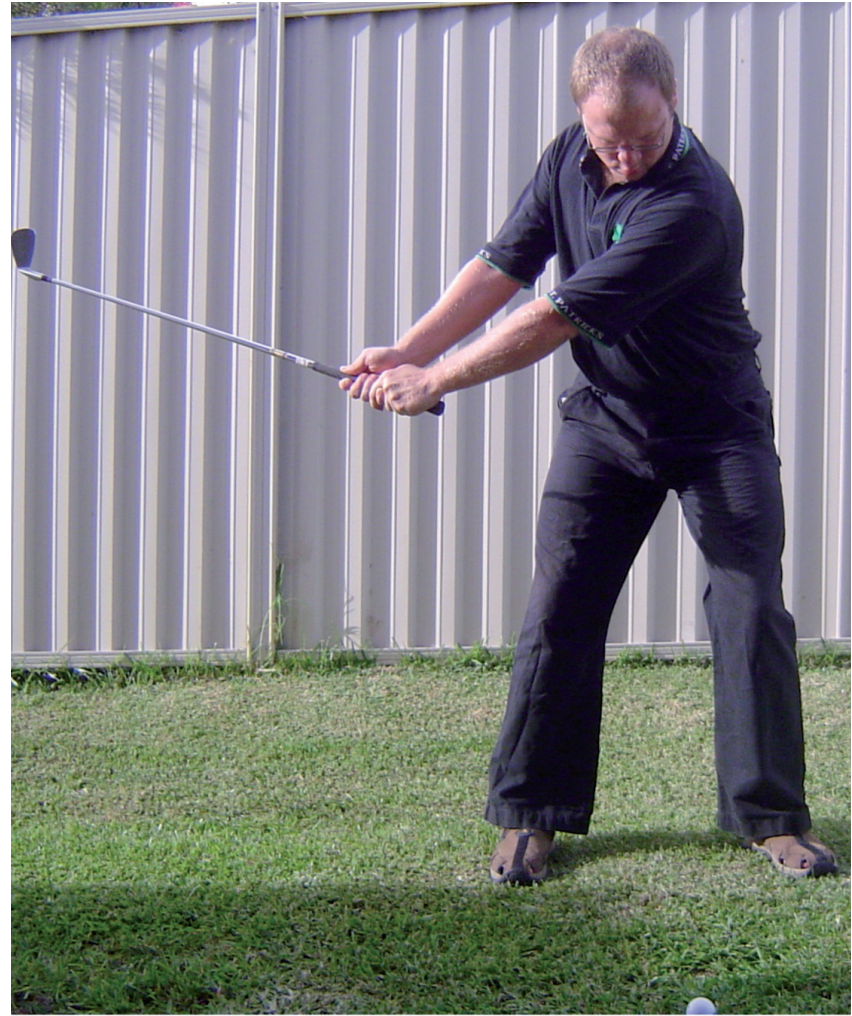

Fig. 2. Backswing phase.

tation and PGA tour and amateurs displayed nearly $90^{\circ}$ rotation. In contrast, Burden et al. ${ }^{6}$ in 1998 found an average of nearly $110^{\circ}$ in a study of 8 sub-10 handicap golfers, with one golfer displaying a shoulder rotation of over $130^{\circ}$. The rota-

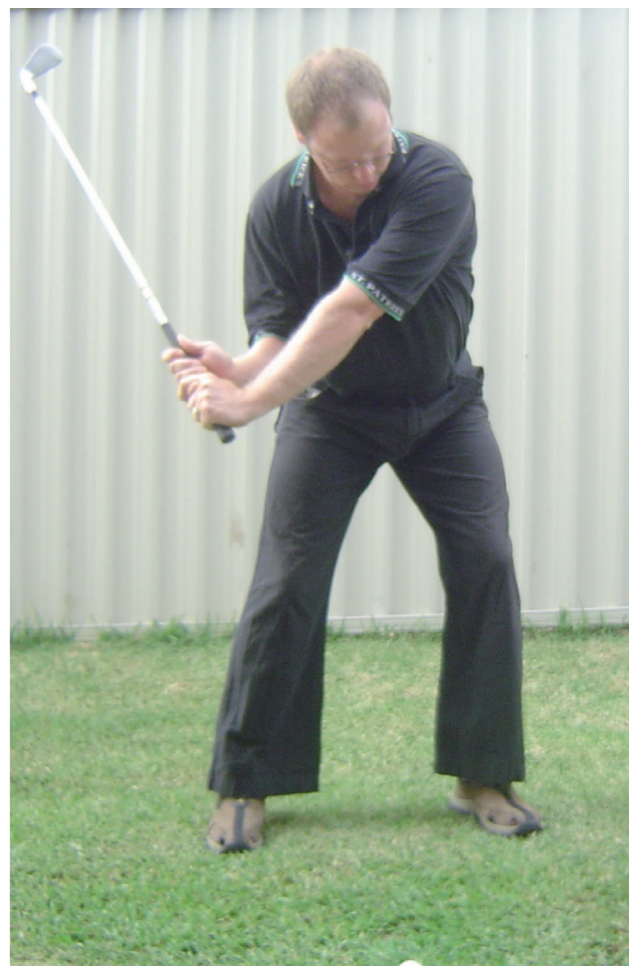

Fig. 3. Downswing phase.

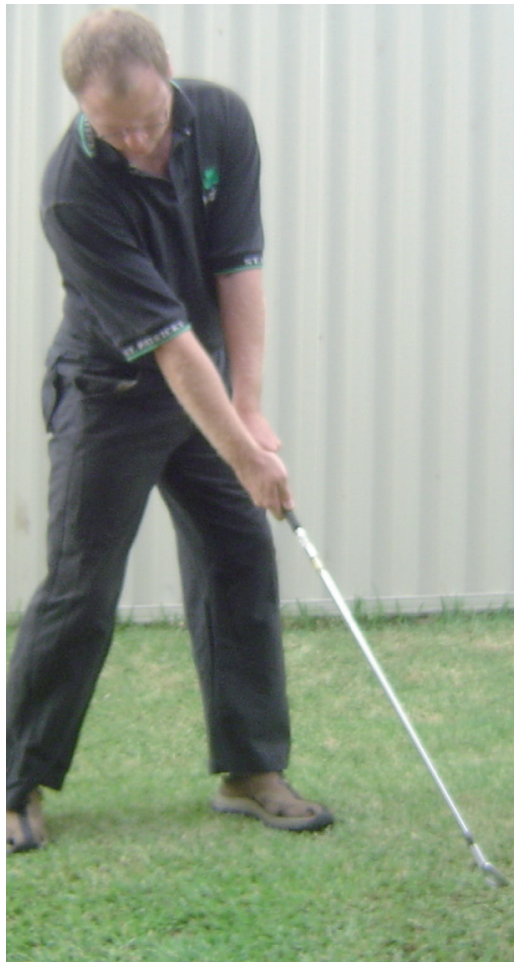

Fig. 4. Follow-through phase.

tion of the upper body is also dependant on the type of shot the golfer wants to play. For example, if a golfer is hitting into the wind the rotation will be less than on other occasions to provide more control than power. Shoulder rotation at the top of the backswing results in the back facing the target, and 

there is between $30^{\circ}$ and $45^{\circ}$ of pelvic rotation, again dependant on golfer characteristics. ${ }^{1,6,37}$

Most of the rotation in the spine occurs at the lumbar and lower thoracic regions, with the differential amount of rotation between the shoulders and the pelvis creating mechanical load on the lower back (Fig. 5). This differential is referred to as the ' $X$ factor', a value rated on the potential power that can be produced during the modern swing. The adoption of this position has been anecdotally related to the predisposition of lower back injuries. ${ }^{36,37}$ It is thought that the higher the $X$ factor (also called the separation angle), the greater the ability to facilitate a higher clubhead speed at impact and hence ball velocity. Cheetham et al., ${ }^{10}$ however, investigated how the $X$ factor changes early in the downswing and found a significantly greater increase in $X$ factor early in the downswing (termed the $X$ factor stretch) in professionals compared with mid-skilled golfers (handicap 15). Cheetham et al. ${ }^{10}$ subsequently suggested that the $X$ factor stretch was more important to an effective swing than simply the $X$ factor achieved at the top of the backswing

The lateral aspect of the left foot lifts off the ground and more weight is borne on the right foot, depending on how much right lateral weight shift the upper body performs. Scientific literature suggests $60-80 \%$ of the weight is borne on the right side, ${ }^{2,43}$ while literature from golf professionals suggests the upper limits of this figure. ${ }^{1}$ The right side of the pelvis acts to stabilise the swing at this point. The main difference in the backswing of the classic swing is that there is a large pelvic turn (also known as hip turn) to accompany the upper body turn (Fig. 5). As a result of the increased hip turn, the separation angle between shoulder and pelvic rotation is less, resulting in less torque being placed on the lower back in the classic swing. More right lateral weight shift is seen in the classic swing compared with the modern swing.

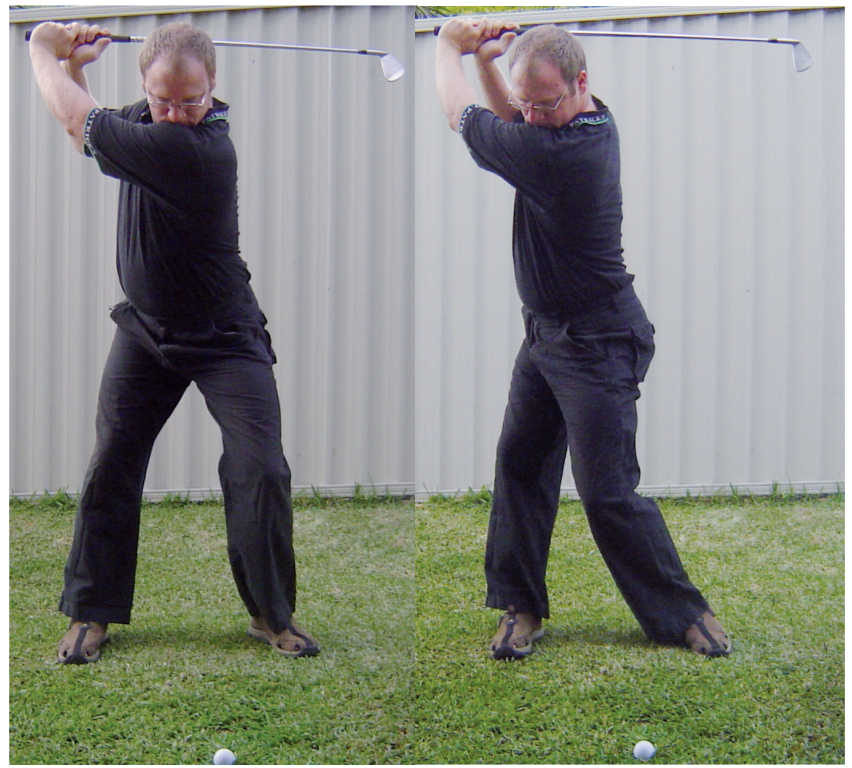

Fig. 5. The modern top of backswing (left) compared with the classic top of backswing (right).
This position places large forces on the acromioclavicular joint that can lead to injury. ${ }^{33}$

\section{The downswing}

The hips initiate the modern downswing, while the whole body initiates the classic downswing. ${ }^{13,43,57}$ In both swings, the left shoulder is adducted across the chest. ${ }^{33,39}$ This phase quickly returns the club back to the ball, with left trunk and hip rotation and a transfer of weight from the right side to the left, resulting in right gluteal and right biceps femoris activation. ${ }^{4,32}$ The left pelvic and hamstring muscles are active to provide a pivot point for the left lumbopelvic rotation and weight transfer is enhanced by the activity of the vastus lateralis and adductor magnus. ${ }^{4,32}$ In the upper body, the combined movement of left rotation of the shoulder girdle and scapular rotation in an anticlockwise direction around the trunk results in large activity of the left medial scapula stabilisers/retractors. ${ }^{15,24,32,33,45}$ Of the rotator cuff muscles, the most active muscle is the subscapularis, more so on the right, while the other cuff muscles display a low level of activity (less than $30 \%$ of manual muscle strength on testing). ${ }^{45}$ Muscle activity on the right side is high in the pectoralis major to initiate internal shoulder rotation and flexion, and the upper serratus anterior contracts to assist scapular protraction. The acceleration phase sees large activity in the left pectoralis major to control left arm abduction and external rotation (eccentric contraction).

\section{Impact}

In the modern swing, pelvic movement leads the upper body at impact. This results in a large degree of right lateral flexion in the spine. ${ }^{21,40,41}$ In comparison, the trunk displays a reduced amount of right lateral flexion in the classic swing, resulting in a reduced compressive load on the right side of the lower back when compared with the modern swing. Maximal axial rotation and right lateral flexion occur just after impact, and the combination of these two movements produces what has been termed the 'crunch factor'. ${ }^{40,41}$ It has been postulated that a high crunch factor is a factor in lower back injury during impact. A significantly higher crunch factor has been found in young adults (18-21 years) when compared with senior (over 50 years) golfers. ${ }^{40}$ In addition, there is a large amount of forearm flexor activity just prior to impact, known as the flexor burst. ${ }^{15}$ Wrist and elbow injuries most commonly occur at impact, particularly when the ground or a tree root is struck (unpublished data). The sudden loading of the softtissue structures of the wrist and elbow may lead to an acute injury if the force is large enough, or insidious overuse injury, with repetition. ${ }^{33}$

The 'hitting zone' (before impact, impact and after impact) is important to every golfer. This is where the power and accuracy of the golf swing merge to produce a successful shot. The clubhead path and alignment in the 12 inches (30 $\mathrm{cm}$ ) either side of impact determine how accurate the golf shot will be. ${ }^{38}$ From a coaching and player perspective, if the 
clubhead is square to the target and the path of the clubhead at pre- and postimpact is square, the ball will travel straight in the intended direction of the flag. However, if they are not, the ball will travel either in a curved path or in a direction that is not straight at the flag. An open clubface at impact will create clockwise spin and a fade/slice, and a closed clubface will create anticlockwise spin and a draw/hook shot. A clubhead that passes from inside to out will result in a ball heading to the right of the target, and a clubhead that passes from outside to in will result in a ball heading to the left of the target. For further discussion of clubhead paths and club alignment at impact, the reader is directed to Miller et al. ${ }^{38}$

\section{Follow-through}

In the modern swing, the upper body lags/trails the pelvis after impact, and results in the lower back adopting a position of extension. This end position is commonly known as the reverse ' $C$ ', ${ }^{39,49}$ a line drawn from the right heel along the leg, up the pelvis and trunk to the left shoulder and head resembles the line drawn by a backwards ' $C$ ' (Fig. 6). This position is quite common in the professional ranks, with high-profile older golfers such as Greg Norman, Fred Couples and Tom Watson displaying it, particularly in their prime. Today's golfers also display this position, including Colin Montgomerie, Tiger Woods and Adam Scott, to name a few. The modern swing transfers much of the swing momentum upwards to achieve greater height during ball flight. ${ }^{17}$ The classic swing displays a relatively straight spine at a similar stage resulting in reduced lumbar extension compared with the modern swing (Fig. 6). The classic swing continues the momentum forward (resulting in a lower ball trajectory) and many of the

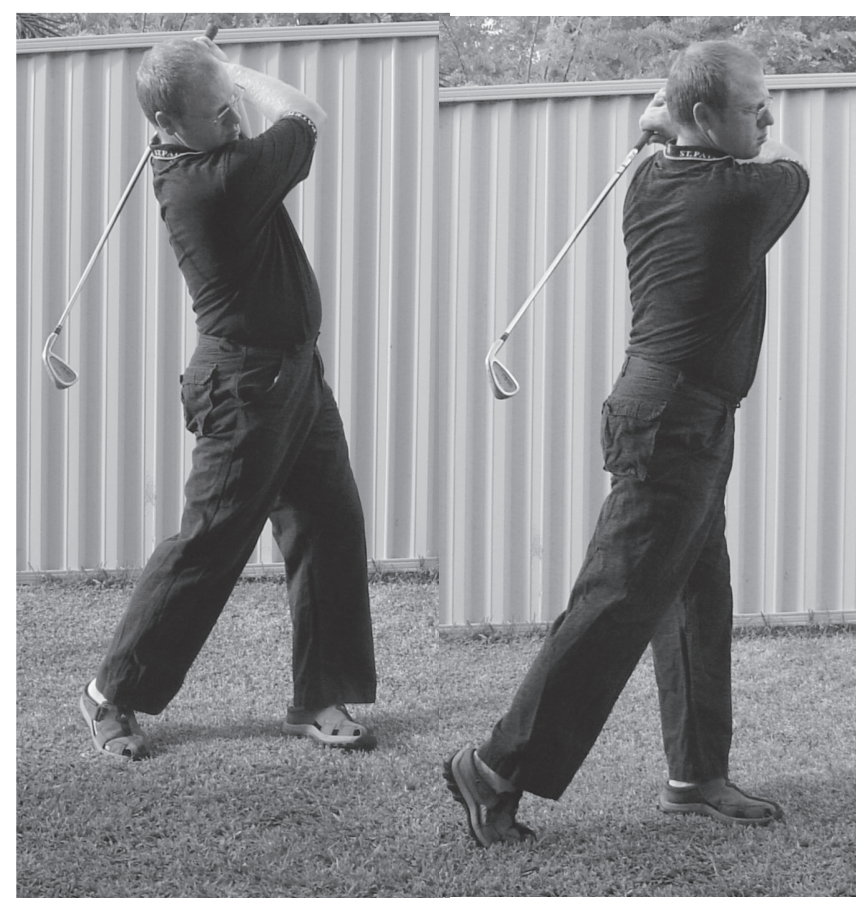

Fig. 6. The modern follow-through (left, with the reverse ' $C$ ') compared with the classic follow-through (right). classic swingers could take a step into a walk after hitting the ball as a result of the forward momentum. ${ }^{31}$ In contrast, the modern swing is completed with the centre of gravity over the legs, with no forward momentum of the body. The follow-through of the golf swing is characterised by continued leg-muscle activity, aiding both weight transfer and left-side stability, while in the early follow-through continued activity occurs of the pectoralis major muscles following from the acceleration phase. ${ }^{32}$ Rotator cuff activity is also high to control the arm movement in this deceleration phase. Injuries to the lower back tend to occur in this phase of the golf swing (unpublished data), while Sugaya et al. ${ }^{50}$ found a correlation of right lower back pain and the follow-through phase of the golf swing in professional golfers.

\section{Epidemiology}

The most common sites of injury in the golfer are dependant on skill level and gender. Depending on which study is cited, professional golfers are most likely to injure their lower back (22 - 24\%), wrist $(20-27 \%)$ and elbow $(7-10 \%) .{ }^{16,30,51}$ Sugaya et al. ${ }^{50}$ found that the lower back and the neck were the two most common injury sites in professional golfers. The most common mechanisms of injury for professional golfers are: repetitive practice of the golf swing and hitting an object other than the ball while swinging the golf club. ${ }^{38}$

In amateur golfers, the sites of injury are most commonly the lower back (15 - 34\%), elbow (25 - 33\%) and wrist (13 - 20\%), with different ranges for male (lower back 25 - 36\%, elbow $18-28 \%$ and wrist $8-33 \%$ ) and female golfers (lower back $22-27 \%$, elbow $6-50 \%$ and wrist $12-36 \%$ ). $3,7,16,29,51$ Researchers ${ }^{29}$ have reported the lower back as the most common site of injury in males while Batt ${ }^{3}$ reported the wrist as the most common site injured. The elbow is a common injury site in golfers, particularly in females ${ }^{3,16}$ with the lateral elbow more commonly injured at a rate of $5: 1 .^{29}$ Overuse through excessive play/practice, poor biomechanics of the swing (e.g. reverse pivot, wrist casting, lumbar hyperextension) and hitting the ground or an object during the swing are the most common injury mechanisms.

Although uncommon, catastrophic injury can result from being hit by a golf ball, and these injuries are the most likely reason for an adult to be admitted to hospital for a golfrelated injury. In children, being struck by a golf club is the most common reason for hospital admission. Adult injuries are most likely to occur on a golf course, while children are more likely to be injured in the home environment. ${ }^{56}$ Further analysis of golf-injury epidemiology is beyond the scope of this paper, and the interested reader is directed to McHardy et al. ${ }^{31}$

\section{Discussion}

The lower back is commonly injured in golf, with many injuries the result of the golf swing. Given that golf has a high participation rate (10\% population), particularly in the over-40 age group, it is likely that patients with golf-related lower back 
injury will present to primary health care providers. Insight into how these injuries may have been sustained is therefore important. Fortunately, a number of previous studies have compared the range of motion of golfers with and without lower back pain. ${ }^{18,26,53}$

$\mathrm{Vad}^{53}$ investigated lumbar and hip range of motion findings between professional golfers with lower back pain and non-sufferers and found that those with pain had significantly decreased lumbar extension, lead hip (left in right-handed golfers) internal rotation and FABERE testing. Lindsay and Horton ${ }^{26}$ in a study of professional golfers with and without lower back pain found that those with lower back pain displayed more lumbar flexion at the address position and exhibited significantly greater left-side bending on the backswing. Those with lower back pain also had less trunk rotation during range of motion testing, which resulted in a relative 'supramaximal' rotation of their spines during the golf swing. ${ }^{26}$ The golfers without pain also demonstrated over twice as much trunk flexion velocity on the downswing. ${ }^{26}$ A further study on abdominal activation in elite male golfers with chronic lower back pain and asymptomatic controls found that abdominal muscle activity and muscle fatigue characteristics were quite similar after repetitive golf swings. ${ }^{18}$ However, those with chronic lower back pain experienced increased lower back pain following repetitive golf swings, suggesting an aggravation of strain on some part of the musculoskeletal system. ${ }^{18}$ However, at no stage did these studies determine what golf swing type subjects displayed. Sugaya et al. ${ }^{50}$ examined lower back pain in righthanded professional golfers and found over half reported experiencing right-side lower back pain, with a correlation between the follow-through phase of the golf swing and right- side lower back pain. Additionally, Hosea et al. ${ }^{20}$ found that peak loading of the lower back occurred during the downswing and that amateur golfers displayed higher peak forces in the golf swing than professional golfers. Once again, at no stage did these studies determine differences between golf swing types. Further analysis of the epidemiology of lower back pain in golfers is beyond the scope of this paper and interested readers are directed to a recent review for a more in-depth discussion. ${ }^{34}$

The subtleties of changes that can occur in the golf swing highlight the potential advantage for the practitioner who understands the golf swing and its variations. The modern golf swing is a popular swing type that has proliferated in the amateur and professional ranks since the 1970s. The reported advantage of the modern golf swing over the more traditional classic golf swing is the higher ball flight achieved. This feature produces a loftier and softer landing approach shot to the green, ${ }^{17}$ which allows the golfer to hit the ball at the flag knowing the ball will stop shortly after landing. Other factors can also influence the golf swing and the trajectory of the ball including: the type of golf club and ball used, impact angles, approach angle of the club to the ball (steep angle or not), lay/position of the ball and the type of shot the golfer wants to play.
While the forces encountered in the lower back during the different swings have not been quantified, anecdotal evidence proposes that the modern golf swing produces more rotational and extension forces in the lower back compared with the forces of the classic swing. ${ }^{34,49}$ The hyperextension of the reverse ' $C$ ' in the modern swing places more stress on the posterior elements of the lower back. ${ }^{37,49}$ These variables, along with a greater right-side compressive load at impact may potentially place the golfer using the modern swing at greater risk of back injury. There exists a need for targeted research into the forces experienced with the different types of golf swing used by today's golfer. The incidence of lower back pain in professionals who use the modern swing compared with those who use the classic swing is unknown. Further investigation into the type of golf swing primarily used by golfers who suffer from lower back pain is required.

Recently, a variation of the modern and classic swing has been introduced to the game of golf. Some golf professionals are now tutoring a swing to golfers that is thought to minimise the impact of the hyperextended modern swing followthrough, while still retaining its power. The hybrid swing displays components of both the classic and modern golf swing. ${ }^{33,34}$ The backswing is similar to the modern swing, with a restricted hip rotation, while the follow-through position is similar to the classic swing, with a relatively neutral spine. Instead of the momentum in the follow-through being directed upwards, like the modern swing, the momentum of the hybrid swing continues to rotate to the left in the right-handed golfer. In doing so, the swing plane that results promotes the much sought-after draw shot, the slight right-to-left movement of the ball during flight. The purpose of the hybrid swing is that it may be prescribed as an alternative to the traditional and classic swings to assist in the rehabilitation of the injured golfer and prevent further injury.

While there are a number of epidemiological studies on golf injuries, none of the studies evaluates whether swing differences influence injury rates. Much of the evidence on which swing predisposes to injury is anecdotal and as such is merely speculation. Further investigation into the differences of the three different golf swings should be undertaken. Investigation into the comparative analysis of specific joint biomechanics (shoulder, elbow and spine in particular) and EMG studies on the shoulder complex and trunk musculature during the different swings are required to determine the most body-friendly golf swing. Further epidemiological studies should evaluate the use of the different golf swings among different populations (young, old, professional, amateur, etc.) to determine if a particular swing is a co-factor in injury. The information in this review is practical in nature and is aimed at providing the clinician with information that can be applied promptly to patients in their practice. It does not attempt to provide kinematic analysis of the two swings, though it concludes that further research into the different swings is required. 


\section{Conclusion}

The golf swing has evolved over time as a result of a combination of advanced equipment, course design and human experimentation. The classic golf swing of old, which involved a large hip rotation accompanying the shoulder rotation and a forward momentum follow-through was replaced by the modern swing because of the increase in power and height of the ball achieved by the new swing. This swing was characterised by a restricted hip rotation with a similar shoulder rotation to the classic swing, causing a large torque between the hips and shoulder and a hyperextended torso in the follow-through (the reverse ' $C$ '). Because of the possibility that these features may predispose the golfer to lower back troubles, a third swing, the hybrid swing, has developed. The hybrid swing is being taught by some golf professionals as a balance between the power-potential of the modern swing and the 'back-friendly' nature of the classic swing, though no studies have so far been conducted on its efficacy. The hybrid swing is characterised by a backswing similar to the modern swing, but a follow-through position like the classic swing, that displays a relatively neutral spine. This swing is hypothesised to reduce the forces on the lower back and hence reduce the chance of golfers sustaining a golf-related lower back injury. While a number of studies have been conducted on the golf swing and its effects on the lower back, no study has evaluated the musculoskeletal effects of the different golf swings. Further investigation into the three golf swings, classic, modern and hybrid, is required to determine which swing is the most effective while also being friendly to the body. Such research will make possible the development programmes aimed at reducing golf injury rates, particularly to the lower back.

\section{REFERENCES}

1. Adlington GS. Proper swing technique and biomechanics of golf. Clin Sports Med 1996; 15: 9-26.

2. Barrentine SW, Fleisig GS, Johnson H, Woolley TW. Ground reaction forces and torques of professional and amateur golfers. In Cochran AJ, Farrally MR, ed. Science \& Golf II. Proceedings of the 1994 World Scientific Congress of Golf, 4-8 July 1994, St. Andrews. London: E and FN Spon, 1994: 33-9.

3. Batt ME. A survey of golf injuries in amateur golfers. $\mathrm{Br} J$ Sports Med 1992; 26: 63-5.

4. Bechler JR, Jobe FW, Pink M, Perry J, Ruwe PA. Electromyographic analysis of the hip and knee during the golf swing. Clin J Sport Med 1995; 5: 162-6.

5. Budney DR, Bellow DG. Kinetic analysis of a golf swing. Res Q 1979; 50: 171-9.

6. Burden AM, Grimshaw PN, Wallace ES. Hip and shoulder rotations during the golf swing of sub 10 handicap players. J Sports Sci 1998; 16: 165-76.

7. Burdorf A, Van Der Steenhoven GA, Tromp-Klaren EG. A one-year prospective study on back pain among novice golfers. Am J Sports Med 1996; 24 (5): 659-64

8. Cahalan TD, Cooney WP 3rd, Tamai K, Chao EY. Biomechanics of the golf swing in players with pathologic conditions of the forearm, wrist, and hand. Am J Sports Med 1991; 19: 288-93.

9. Carlsoo S. A kinetic analysis of the golf swing. J Sports Med Phys Fitness 1967; 7: 76-82.

10. Cheetham PJ, Marti, PE, Mottram RE, St Laurent BF. The importance of stretching the 'X-Factor' in the downswing of golf: the 'X-Factor stretch'. 2000 Pre-Olympic Congress Sports Medicine and Physical Education.
International Congress on Sport Science. 7-13 September, Brisbane, Australia 2000, 195

11. Egret $\mathrm{Cl}$, Nicolle B, Dujardin FH, Weber J, Chollet D. Kinematic analysis of the golf swing in men and women experienced golfers. Int J Sports Med 2006; 27: 463-7.

12. Egret $\mathrm{Cl}$, Vincent $\mathrm{O}$, Weber J, Dujardin FH, Chollet D. Analysis of 3D kinematics concerning three different clubs in golf swing. Int J Sports Med 2003; 24: 465-70.

13. Gatt CJ Jr, Pavol MJ, Parker RD, Grabiner MD. Three-dimensional knee joint kinetics during a golf swing. Influences of skill level and footwear. Am J Sports Med 1998; 26: 285-94.

14. Geisler PR. Golf. In: Shamus E, Shamus J, eds. Sports Injury Prevention and Rehabilitation. New York: McGraw-Hill, 2001.

15. Glazebrook MA, Curwin S, Islam MN, Kozey J, Stanish WD. Medial epicondylitis. An electromyographic analysis and an investigation of intervention strategies. Am J Sports Med 1994; 22: 674-9.

16. Gosheger G, Liem D, Ludwig K, Greshake O, Winkelmann W. Injuries and overuse syndromes in golf. Am J Sports Med 2003; 31: 438-43.

17. Hawkes C. The Swing. The Secrets of the Game's Greatest Golfers. London: Carlton Books, 2001: 15

18. Horton JF, Lindsay DM, Macintosh BR. Abdominal muscle activation of elite male golfers with chronic low back pain. Med Sci Sports Exerc 2001; 33: $1647-54$

19. Hosea TM, Gatt CJ. Back pain in golf. Cl Sports Med 1996; 15: 37-53.

20. Hosea TM, Gatt CJ, Galli KM, Langrana NA, Zawadsky JP. Biomechanical analysis of the golfer's back. In Cochran AJ, ed. Science \& Golf I. Proceedings of the World Scientific Congress of Golf, 9-13 July 1990, St. Andrews. London: E and FN Spon, 1990: 43-8.

21. Hume PA, Keogh J, Reid D. The role of biomechanics in maximising distance and accuracy of golf shots. Sports Med 2005; 35: 429-49.

22. Jobe FW, Perry J, Pink M. Electromyographic shoulder activity in men and women professional golfers. Am J Sports Med 1989; 17: 782-7.

23. Jobe FW, Moynes DR, Antonelli DJ. Rotator cuff function during a golf swing. Am J Sports Med 1986; 14: 388-92.

24. Kao JT, Pink M, Jobe FW, Perry J. Electromyographic analysis of the scapular muscles during a golf swing. Am J Sports Med 1995; 23: 19-23.

25. Kawashima K, Meshizuka T, Takaeshita S. A kinematic analysis of foot force exerted on the soles during the golf swing among skilled and unskilled golfers. In: Farrally MR, Cochran AJ, eds. Science \& Golf III. Proceedings of the 1998 World Scientific Congress of Golf; 20-24 July 1998, St Andrews. Champaign, IL: Human Kinetics, 1999: 40-5.

26. Lindsay D, Horton J. Comparison of spine motion in elite golfers with and without low back pain. J Sports Sci 2002; 20: 599-605.

27. Lindsay DM, Horton JF, Paley RD. Trunk motion of male professional golfers using two different golf clubs. J Appl Biomech 2002; 18: 366-373.

28. Maddalozzo, J. 1987. An anatomical and biomechanical analysis of the full golf swing. NSCA Journal 1987; 9: 4-7.

29. McCarroll, Retting AC, Shelbourne KD. Injuries in the amateur golfer. Phys Sports Med 1990; 18: 122-26.

30. McCarroll JR, Gioe TJ. Professional golfers and the price they pay. Phys Sports Med 1982; 10: 64-70.

31. McHardy A, Pollard H, Luo K. Golf injuries: A review of the literature. Sports Med 2006; 36: 171-87.

32. McHardy A, Pollard $\mathrm{H}$. Muscle activity during the golf swing. $\mathrm{Br} \mathrm{J}$ Sports Med 2005; 39: 799-804.

33. McHardy A, Pollard $\mathrm{H}$. Golf and upper limb injuries: a summary and review of the literature. Chiropractic \& Osteopathy 2005; $13: 7$

34. McHardy A, Pollard H. Lower back pain in golfers: A review. J Chiro Med 2005; 4: 135-143.

35. McLaughlin PA, Best RJ. Three-dimensional kinematic analysis of the golf swing. In: Cochran AJ, Farrally MR, eds. Science \& Golf II. Proceedings of the 1994 World Scientific Congress of Golf; 4-8 July 1994, St Andrews. London: E \& FN Spon, 1994: 91-6

36. McLean J. The X-Factor Swing. New York, NY: HarperResource, 1997.

37. McTeigue M, Lamb S, Mottram R, Pirozzolo F. Spine and hip motion analysis during the golf swing. In Cochran AJ, Farrally MR, eds. Science \& Golf II. Proceedings of the 1994 World Scientific Congress of Golf: 4-8 July 1994, St. Andrews. London: E and FN Spon, 1994: 50-8.

38. Miller GA, Cross TS, Barnhart TC. Golf instruction: learning from the flight of the golf ball. JOPERD 1992; 63: 17-20. 
39. Mitchell K, Banks S, Morgan D, Sugaya H. Shoulder motions during the golf swing in male amateur golfers. J Orthop Sports Phys Ther 2003; 33: 196-203.

40. Morgan DA, Cook F, Banks SA. The influence of age on lumbar mechanics during golf swing. In: Farrally MR, Cochran AJ, eds. Science \& Golf III. Proceedings of the World Scientific Congress of Golf. Champaign IL: Human Kinetics, 1998: 120-6.

41. Morgan DA, Sugaya $H$, Banks SA, Cook F. A New Twist on Golf Kinematics and Low Back Injuries. Proceedings of the 21st Annual Meeting of the American Society of Biomechanics 1997. Clemson University, South Carolina, 24 - 27 September 1997.

42. Neal RJ, Wilson BD. 3D kinematics and kinetics of the golf swing. Int $J$ Sport Biomech 1985; 1: 221-32.

43. Okuda I, Armstrong CW, Tsunezumi H, Yoshiike $\mathrm{H}$. Biomechanical analysis of professional golfer's swing: Hidemichi Tanaka. In Thain E, ed. Science \& Golf IV. Proceedings of the World Scientific Congress of Golf, 23-26 July 2002, St. Andrews. London: E and FN Spon, 2002: 18-27.

44. Pink M, Perry J, Jobe FW. Electromyographic analysis of the trunk in golfers. Am J Sports Med 1993; 21: 385-8.

45. Pink M, Jobe FW, Perry J. Electromyographic analysis of the shoulder during the golf swing. Am J Sports Med 1990; 18: 137-40.

46. Rehling $\mathrm{CH}$. Analysis of techniques of the golf drive. Res $Q 1955 ; 26$ : 80-81.

47. Richards J, Farrell M, Kent J, Kraft R. Weight transfer patterns during the golf swing. Res Q Exerc Sport 1985; 56: 361-513.

48. Sherman CA, and Finch CF. The ideal golf swing: an evaluation of its mechanics and relationship to injury risk. Safety Science Monitor 1999; 3: 1-8.
49. Stover CN, Wiren G, Topaz SR. Modern golf swing and stress syndromes. Phys Sportsmed 1976; 4: 42-7.

50. Sugaya H, Tschiya A, Moriya H, Morgan DA, Banks SA. Low-back injury in elite and professional golfers an epidemiologic and radiographic study. In Farrally MR, Cochran AJ, ed. Science \& Golf III. Proceedings of the World Scientific Congress of Golf, $20-24$ July 1998, St. Andrews. Champaign, IL: Human Kinetics, 1998: 83-91.

51. Theriault G, Lacoste E, Gaboury M, et al. Golf injury characteristics: a survey of 528 golfers. Med Sci Sports Exerc 1996; 28: S65.

52. Tsai Y. Biomechanical and physical characteristics of trunk and hip in golfers with and without low back pain. 2005. PhD Dissertation, University of Pittsburgh.

53. Vad VB, Bhat AL, Basrai D, Gebeh A, Aspergren DD, Andrews JR. Low back pain in professional golfers: the role of associated hip and low back range-of-motion deficits. Am J Sports Med 2004; 32: 494-7.

54. Wallace ES, Grimshaw PN, Ashford RL. Discrete pressure profiles of the feet and weight transfer patterns during the golf swing. In: Cochran AJ Farrally MR, eds. Science \& Golf II. Proceedings of the 1994 World Scientific Congress of Golf, 4-8 July 1994, St Andrews. London: E \& FN Spon, 1994: 26-32.

55. Watkins RG, Uppal GS, Perry J, Pink M, Dinsay JM. Dynamic electromyographic analysis of trunk musculature in professional golfers. Am J Sports Med 1996; 24: 535-8.

56. Wilks J, Jones D. Golf-related injuries seen at hospital emergency departments. Aust J Sci Med Sport 1996; 28: 43-5

57. Williams KR, Cavanagh PR. The mechanics of foot action during the golf swing and implications for shoe design. Med Sci Sports Exerc 1983; 15: 247-255
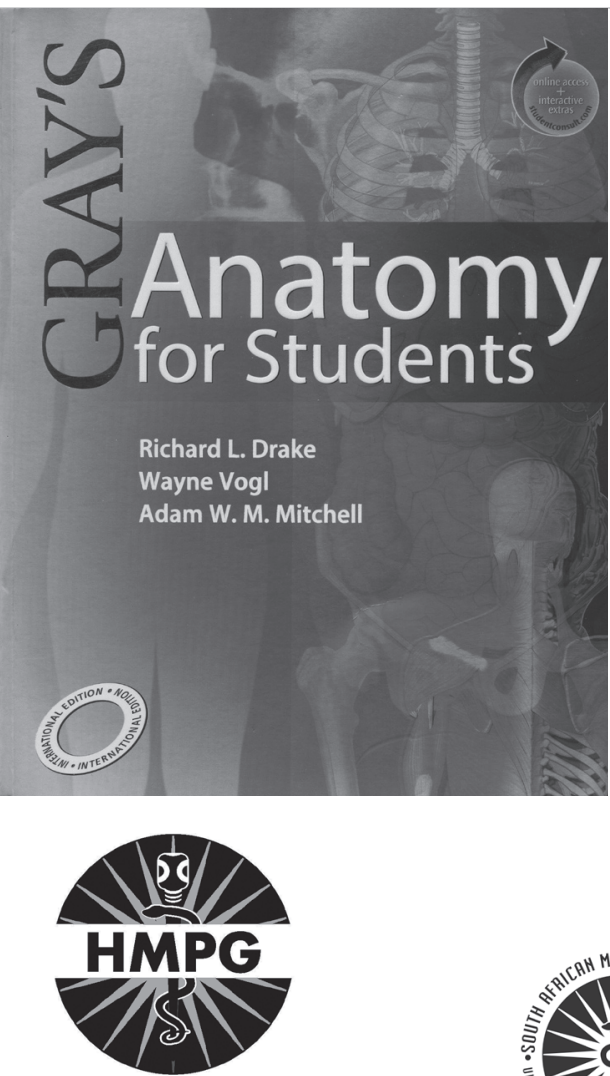

\section{Health \& Medical Books}

\section{Health \& Medical Publishing Group Private bag X1, Pinelands, 7430} Tel: 021-6578200 Fax: 021-6834509 e-mail:carmena@hmpg.co.za brents@hmpg.co.za 